\title{
The Palermo (Sicily) seismic cluster of September 2002, in the seismotectonic framework of the Tyrrhenian Sea-Sicily border area
}

\author{
Giuseppe Giunta $\left({ }^{1}\right)$, Dario Luzio $\left({ }^{2}\right)$, Emanuele Tondi $\left({ }^{3}\right)$, Luciana De Luca $\left({ }^{2}\right)$, Alessandra Giorgianni $\left({ }^{1}\right)$, \\ Giuseppe D'Anna $\left({ }^{4}\right)$, Pietro Renda $\left({ }^{1}\right)$, Giuseppe Cello $\left.{ }^{3}\right)$, Fabrizio Nigro $\left({ }^{1}\right)$ and Massimo Vitale $\left({ }^{2}\right)$ \\ (1) Dipartimento di Geologia e Geodesia, Università degli Studi di Palermo, Italy \\ ${ }^{(2)}$ Dipartimento di Chimica e Fisica della Terra (CFTA), Università degli Studi di Palermo, Italy \\ (3) Dipartimento di Scienze della Terra, Università degli Studi di Camerino, Italy \\ ${ }^{4}{ }^{4}$ Istituto Nazionale di Geofisica e Vulcanologia, Roma, Italy
}

\begin{abstract}
The northern coast of Sicily and its offshore area represent a hinge zone between a sector of the Tyrrhenian Basin, characterized by the strongest crustal thinning, and the sector of the Sicilian belt which has emerged. This hinge zone is part of a wider W-E trending right-lateral shear zone, which has been affecting the Maghrebian Chain units since the Pliocene. Seismological and structural data have been used to evaluate the seismotectonic behavior of the area investigated here. Seismological analysis was performed on a data set of about 2100 seismic events which occurred between January 1988 and October 2002 in the Southern Tyrrhenian Sea. This paper focuses in particular on a set of data relating to the period from 6th September 2002, including both the main shock and about 540 aftershocks of the Palermo seismic sequence. The distribution of the hypocenters revealed the presence of two main seismogenic zones. The events of the easternmost zone may be related to the Ionian lithospheric slab diving beneath the Calabrian Arc. The seismicity associated with the westernmost zone is closely clustered around a sub-horizontal regression plane contained within the thinned Southern Tyrrhenian crust, hence suggesting that this seismogenic zone is strictly connected to the deformation field active within the hinge zone. On the basis of both structural and seismological data, the brittle deformation pattern is characterized by high-angle faults, mainly represented by transcurrent synthetic right-lateral and antithetic left-lateral systems, producing both restraining/uplifting and releasing/subsiding zones which accommodate strains developing in response to the current stress field (characterized by a maximum axis trending NW-SE) which has been active in the area since the Pliocene. The cluster of the seismic sequence which started with the 6th September 2002's main shock is located within the hinge zone. The distribution of the hypocenters relative to this sequence emphasizes the presence of a high-angle NE-SW-oriented deformation belt within which several shear surfaces are considered to be found sub-parallel to that established for the main shock. The kinematics of all these structures is consistent with a compressive right-lateral focal mechanism.
\end{abstract}

Key words seismotectonics - Southern Tyrrhenian Sea - Northwestern Sicily

Mailing address: Dr. Giuseppe Giunta, Dipartimento di Geologia e Geodesia, Università degli Studi di Palermo, C.so Tukory 131, 90134 Palermo, Italy; e-mail: giuntape@unipa.it

\section{Introduction}

The recent seismicity (1988-2002) around the border between the Southern Tyrrhenian Sea and Northern Sicily, including the 2002 Palermo seismic sequence, highlights some geological aspects from a seismotectonic perspective. 
The geological structure of the Northern Sicilian-Maghrebian Chain is reasonably wellknown, even though there may be some disagreement regarding: 1) the hierarchical level of neotectonic structures consequent on the main crustal shortening phase (Late Oligocene - Early-Middle Miocene); 2) the purely extensional or strike-slip character of their features from the Late Miocene to the Quaternary; and 3) the existence of still active thrust surfaces in the northernmost portion of the chain.

The seismic profiles available demonstrate a tectonic style related with the phase of thrusting, while the high-angle structures crossing the thrust surfaces are not always well defined (Finetti et al., 1996; Pepe et al., 2000). Some of the post-thrust fault systems are active today, although the limited data to hand do not permit recognition of the seismogenetic segments. On the other hand, the Southern Tyrrhenian, where the recent seismicity is located, has not yet been well documented from a structural point of view.

Over the last few years, a research group, including structural geologists and geophysicists from the Universities of Palermo, Camerino, Padova and INGV, has been studying both the neotectonic and the seismicity of the area between the Southern Tyrrhenian and Northern Sicily, in an attempt to outline a seismotectonic model for this area, by: 1) reconstructing the sequential order of the neotectonic deformations on land; 2) identifying the offshore fault pattern, processing in different ways the morphobathymetric maps; 3) performing a fractal analysis of the fault grid and morphostructural lineaments; 4) relocating and analysing clusters of the seismic events; 5) studying the focal mechanisms of the most energetic shocks; and 6 ) characterizing the geometry of both the seismogenetic volumes and their fracturing styles.

The present paper represents a preliminary attempt to improve our understanding of the Southern Tyrrhenian seismotectonic processes.

\section{Structural outlines}

The data available on the Southern Tyrrhenian crust, relating to wide-angle and deep near vertical seismic profiles, Bouguer and magnetic anomalies maps and heat-flow data, indicate that crustal thickness increases from the Southern Tyrrhenian abyssal plane to the Sicilian mainland (fig. 1), from about $15 \mathrm{~km}$ to $30-35 \mathrm{~km}$

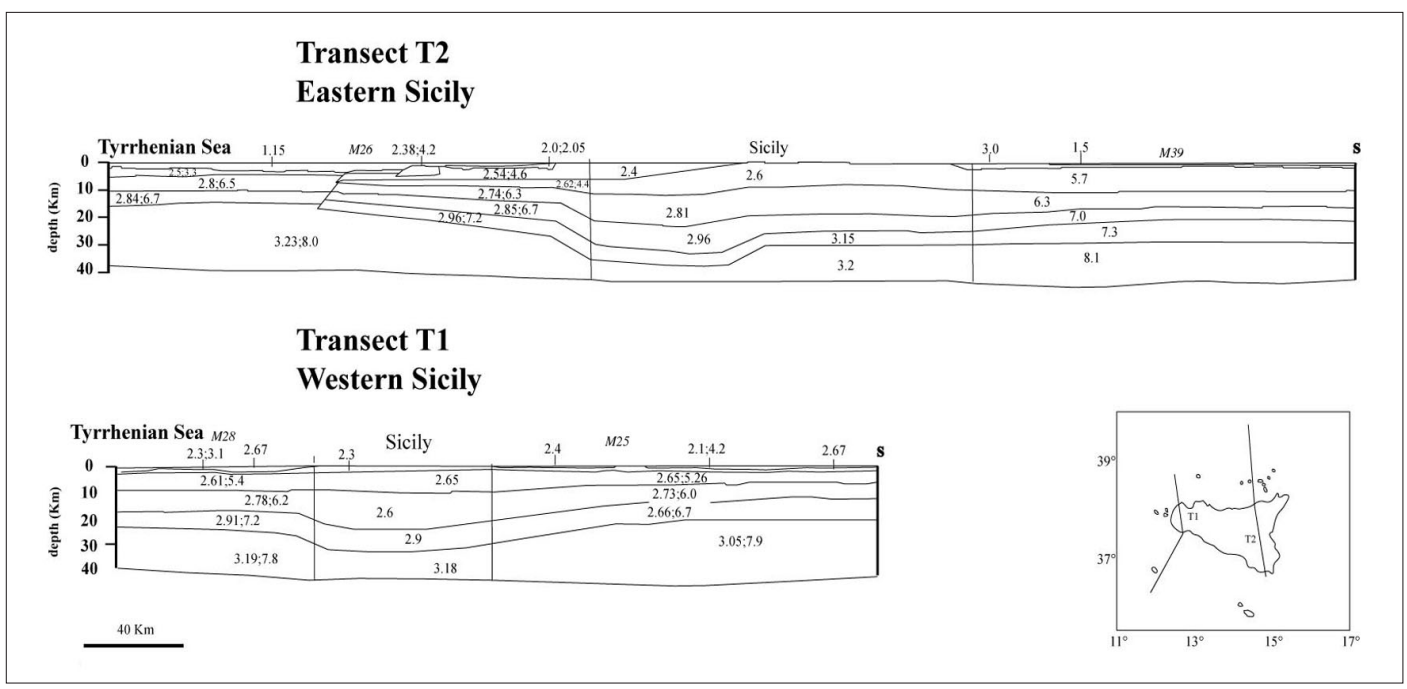

Fig. 1. Seismic and gravimetric interpretation along transects $\mathrm{T} 1$ and $\mathrm{T} 2$. The numeric values refer to density $\left(\mathrm{g} / \mathrm{cm}^{3}\right)$; where double, they refer, respectively, to density and velocity $(\mathrm{km} / \mathrm{s})($ from Chironi et al., 2000). 


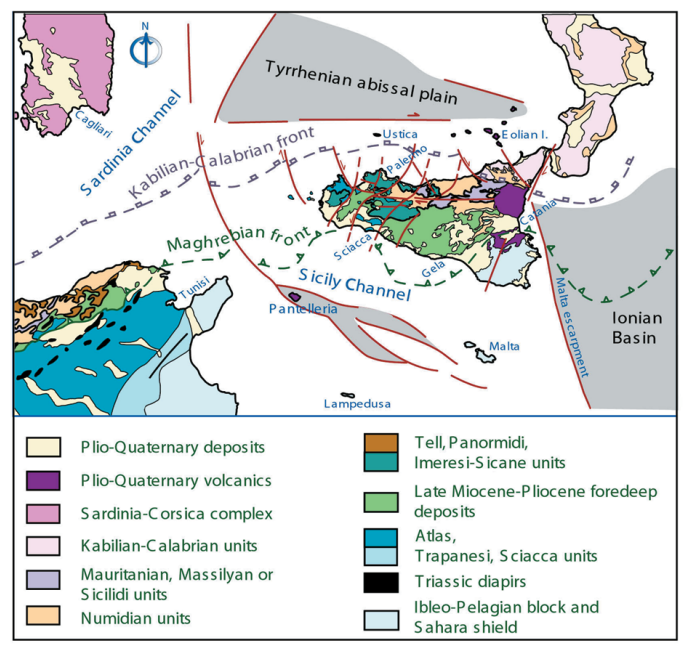

Fig. 2. Schematic structural map of the Central Mediterranean (modified from Giunta et al., 2002a).
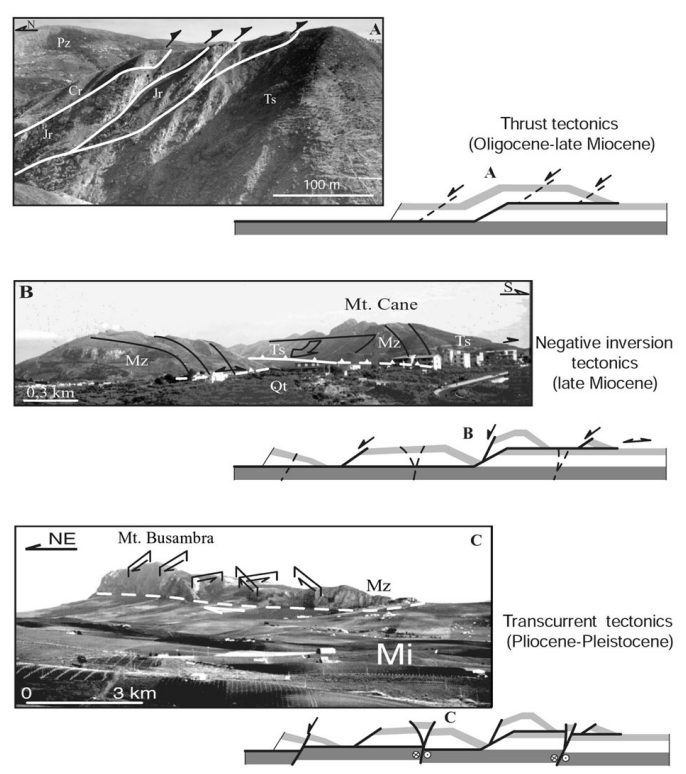

Fig. 3. Sequential order of deformation in Northern Sicily. The pictures represent examples from: A Peloritani Mts.; B - Termini Mts.; C - Palermo Mts. (modified from Giunta et al., 2002b); Pz - Paleozoic; Ts - Triassic; Jr - Jurassic; Cr - Cretaceous; Mz Mesozoic; Mi - Miocene; Qt - Quaternary.
(Chironi et al., 2000). This crustal thickness variation follows a major structural feature which extends E-W for about $400 \mathrm{~km}$, separating a sector of the Southern Tyrrhenian Basin characterized by the strongest crustal thinning (Finetti and Del Ben, 1986) from the sector of the Sicilian belt which has emerged, where crustal thickening occurred mostly by thrust stacking during mountain building (fig. 2).

The main steps in the sequential order of deformation (Giunta et al., 2000a) of the Northern Sicilian-Maghrebian orogen are as follows (fig. 3): 1) flat-ramp thrust tectonics, including duplexing and imbrications with southward vergence, occurred from the Early Miocene on; 2) inversion tectonics (mainly negative) with a northward vergence, stretching the previously formed collisional belt, developed from the Late Miocene on; and 3) high-angle faults have dissected the whole structure of the belt, often reactivating pre-existing structures, since the PlioPleistocene, thereby constraining the evolution of the Northern Sicily-Southern Tyrrhenian hinge zone.

Such a hinge zone corresponds more or less to the area bordered to the south by the so-called Kumeta-Alcantara line (Ghisetti and Vezzani, 1984) and to the north by the Ustica-Eolie alignment (Boccaletti et al., 1982). It is to be included in a wider W-E trending right-lateral shear zone (Giunta, 1985; Giunta et al., 2000b) activated in the area since the Pliocene (Ghisetti and Vezzani, 1984), which extends from the UsticaEolie line to the Sicilian Channel (fig. 4). The kinematic model proposed by Giunta et al. (2000b) explains the main structural features and evolution of this shear zone (fig. 5). According to this model, the neotectonic fault grid seems to be consistent with the W-E shear zone assumption. Various fault systems have been recognized, both on land and offshore (fig. 6). They may be classified as follows: 1) a right-lateral fault system mainly trending NW-SE and W-E, and 2) a left-lateral fault system mainly trending N-S and NE-SW. Each is characterized by high-angle fault surfaces with transpressional or transtensional kinematics, hence allowing the formation of either restraining or releasing band structures.

Several segments of these fault systems have deformed very recent deposits (Nigro et al., 


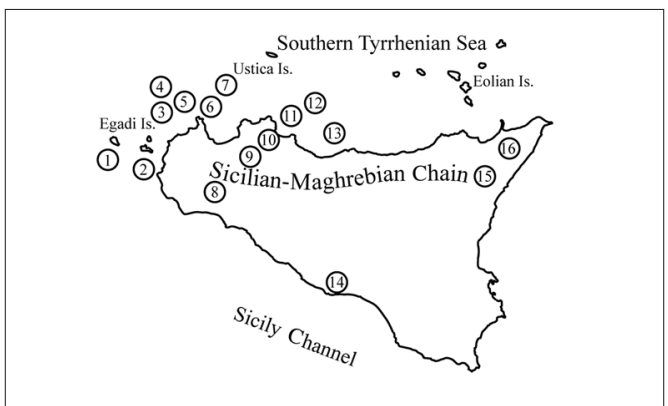

Fig. 4. Localities cited in the text: 1 - Marettimo; 2 Favignana; 3 - Banco Scuso; 4 - Trapani Basin; 5 Erice Basin; 6 - Peninsula of San Vito; 7 - Castellammare Basin; 8 - Belice Valley; 9 - Mt. Kumeta; 10 Palermo; 11 - Palermo Basin; 12 - Mt. Soluto; 13 Cefalù Basin; 14 - Gela; 15 - Mt. Etna; 16 - Alcantara River.
2000), suggesting that the present-day activity might be connected with the shallow seismicity occurring between the Ustica-Eolie alignment and Northern Sicily. The above-mentioned faults (fig. 6) are all consistent with strain partitioning within a right-lateral $\mathrm{W}-\mathrm{E}$ trending shear zone. Second-order structures related to the UsticaEolie and Kumeta-Alcantara lines are represented by certain NW-SE trending faults (such as the Marettimo, Trapani, San Vito, and Palermo faults), extending for less than $100 \mathrm{~km}$ in Northern Sicily and its offshore zone. These structures have been interpreted as synthetic Riedel $(R)$ shears with respect to the main W-E faults (Nigro et al., 2000). A few Plio-Pleistocene releasing bends, as well as the strongly subsiding tectonic depressions of the Trapani, Erice, Castellammare, Palermo, and Cefalù basins, are all located

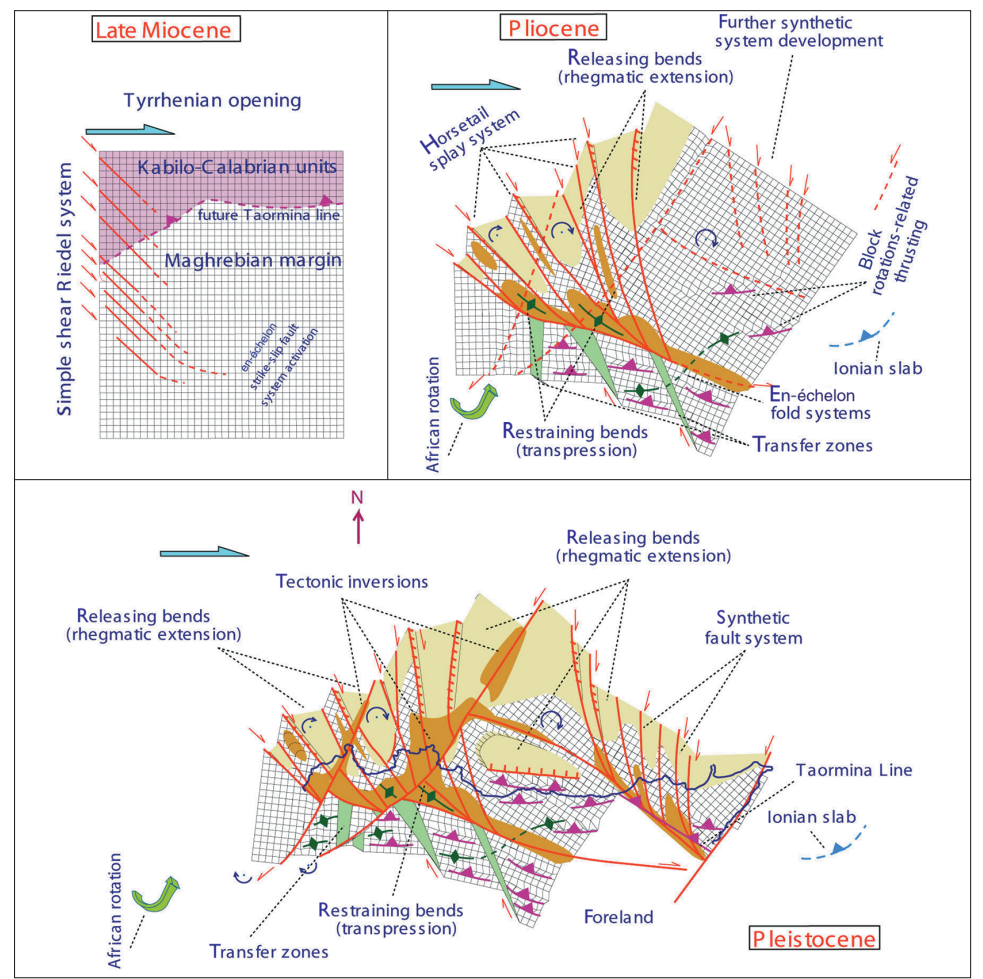

Fig. 5. Reconstruction of the neotectonic evolution of the Northern Sicilian-Maghrebian Chain (modified from Giunta et al., 2000b), based on the deformation in a simple shear of a grid of finite square elements. The simple shear mechanism seems to be induced by the counterclockwise rotation of the stable Africa and the variable clockwise rotation of the detached tectonic units of the chain. 


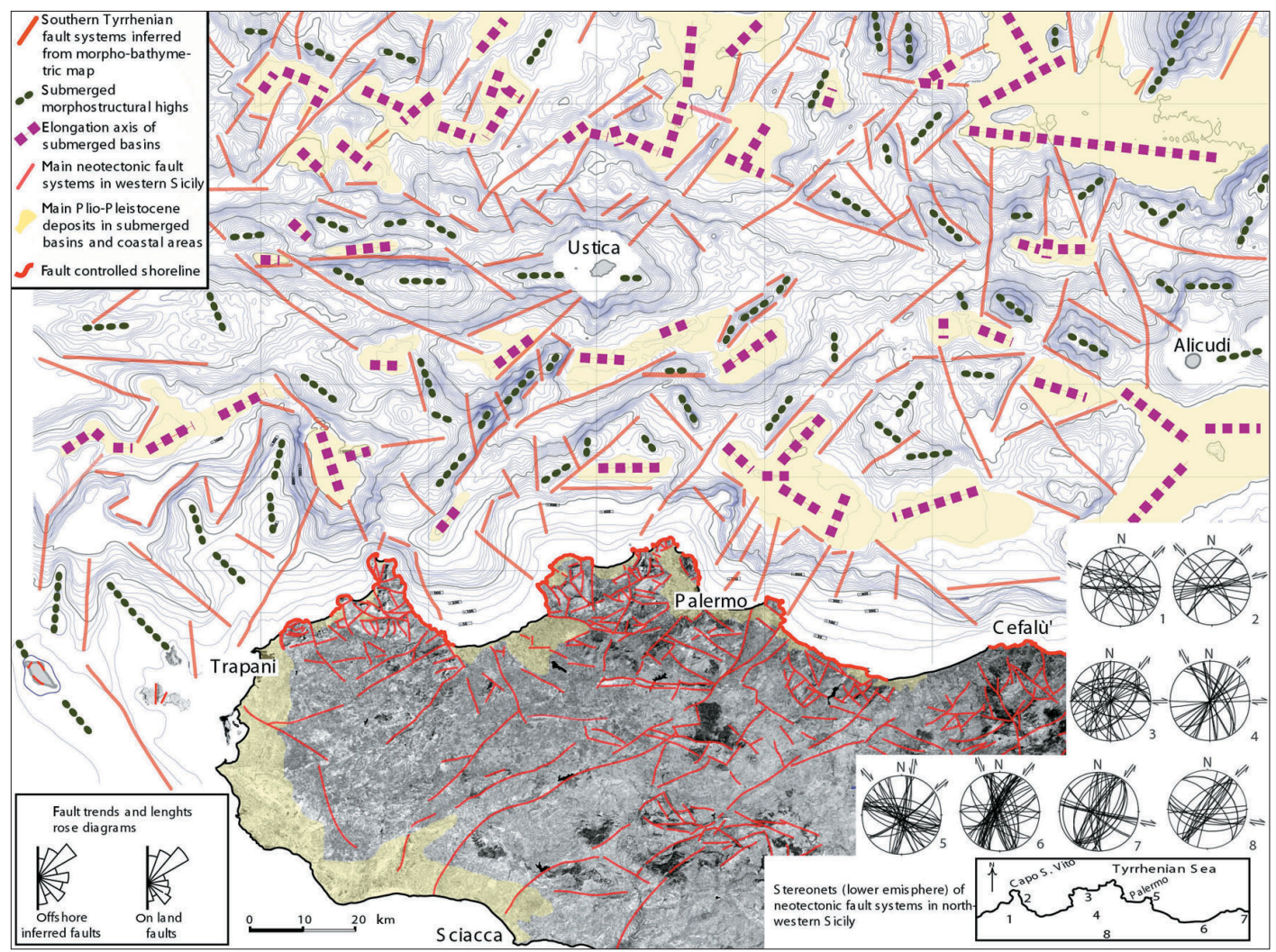

Fig. 6. Neotectonic schematic map of the Southern Tyrrhenian Sea and North-Western Sicily. The main fault onshore lineaments are drawn on a Landsat image, while the offshore ones represent fault systems inferred from a multi-scale processing of the bathymetric map by the Institute of Marine Geology of the Italian National Research Council.

in the overstep zones between the NW-SE trending faults. These fault-controlled basins are interposed between the restraining zones represented by the morphostructural highs of the San Vito Peninsula, the Palermo mountains, the Banco Scuso and Solunto which, in places, extend from coastal to submarine sectors (Giunta et al., 2000b). Other minor structures are variously oriented but kinematically compatible with the Ustica-Eolie and Kumeta-Alcantara lines, as well as with the Marettimo, Trapani, and San Vito faults.

Both the NW-SE and the W-E/WNW-ESE trending structures are, in places, progressively offset by an antithetic fault system trending ap- proximately NE-SW. The main faults of the NE-SW trending system border the Trapani and Palermo mountains to the east. The kinematic indicators on the fault planes highlight a mainly transpressive left-lateral transcurrent motion.

\section{Geometric, kinematic and dimensional properties of the Late-Quaternary fault systems}

The epicentral zone of the September 2002 Palermo earthquake lies in the offshore sector of the Sicilian-Maghrebian Chain. The distribution 


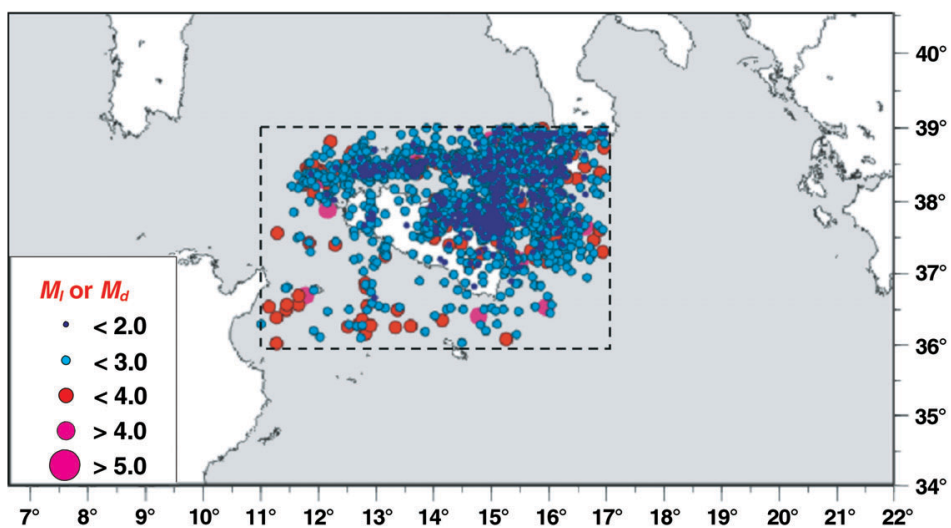

Fig. 7. Epicentral distribution of the events occurred after 1988 in the Sicilian area (dotted rectangle). The epicentres were extracted from the INGV catalogue.

of the earthquakes which have occurred over the last 25 years in Sicily and in its surrounding basins (fig. 7) shows that this sector is characterized by a much higher seismicity rate than that of the onshore area, except for that of Etna. In spite of this apparent heterogeneity, the presence of a continuous right-lateral shear stress field in this geodynamic province could justify the assumption of homogeneity of the main geometric features of the lineament distributions in the two sectors. For this reason, a seismotectonic model of this portion of the Central Mediterranean Sea should be based on the possibility of extrapolating the style and deformation modes observed on land to the offshore seafloor. This approach may be better sustained if the geometrical, dimensional and directional properties of the structures occurring in both sectors are somehow comparable. With the aim of comparing the two sets of morphostructures (on land and offshore), accurate maps are first derived of the major morphostructural lineaments exposed on land and showing evidence of recent activity, by interpreting satellite images and aerial photographs at different scales (fig. 8a). The main morphostructural lineaments were subsequently recognized by interpreting detailed maps of the sea bottom of the Northern Sicily-offshore area (figs. 6 and 8a; CNR, Istituto di Geologia Marina of Bologna, Italy).
The main parameters which were compared in our analysis include: 1) the frequency distribution of faults strikes; 2) the surface density of morphostructural lineaments; and 3) the frequency distribution of lineament lengths.

The comparison between the directional features of the analyzed structures indicates that in both sectors the prevalent direction of the faults is NNE-SSW and NE-SW (fig. 6).

The dimensional and spatial characteristics of the structures exposed (Cello, 1997), and their degree of structural maturity, were analyzed using 2D fractal methodologies in the two zones.

Fractal analysis was applied to the derived morphostructural lineament patterns of both sectors by using the box-counting technique (Mandelbrot, 1982; Walsh and Wafterson, 1992). The fractal dimension estimate $D$ (fig. $8 \mathrm{~b}, \mathrm{e})$ for the two sectors was 1.2 and 1.3 respectively, suggesting that both sectors are characterized by a rather low degree of maturity.

Further data on fault properties were derived by calculating the exponent $c$ of the power laws describing the frequency distribution of lineament lengths both on land and offshore (fig. 8c,d). Their exponent $c$ values turned out to be approximately equal to 1.7 and $1.6 \mathrm{re}-$ spectively. These values also indicate a low degree of structural maturity (Sornette et al., 1990; Cowie et al., 1993), hence suggesting 
that this result is compatible with that inferred from box-counting analysis.

In conclusion, the results illustrated above seem to support the hypothesis that the Late
Quaternary faults observed and inferred in both of the sectors in question show similar geometric, kinematic and dimensional properties. This in turn allows us to be more confident in ex-
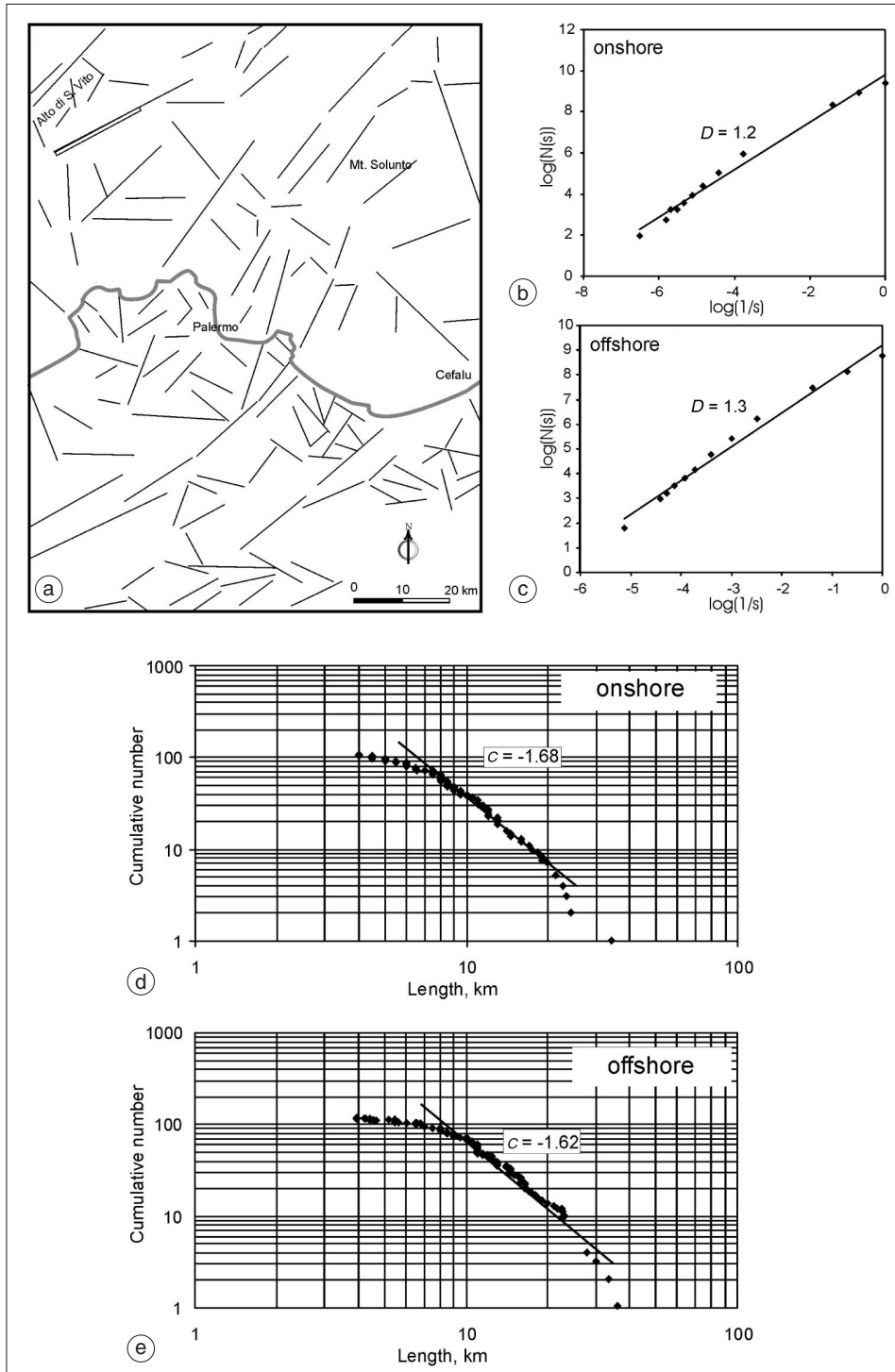

Fig. 8a-e. a) Major morphostructural lineaments exposed onshore and offshore. Bilogarithmic diagrams obtained from box-counting analysis applied to the morphotectonic lineaments onshore (b) and offshore (c). Cumulative-frequency distribution of lineaments length observed onshore (d) and offshore (e). 
trapolating from results and interpretations deriving from the geological-structural analyses carried out in the field to the offshore features inferred in the epicentral areas of the recent Southern Tyrrhenian seismicity.

\section{Southern Tyrrhenian seismicity}

The seismicity of the Southern Tyrrhenian is characterized by numerous events of medium-low magnitude. From 1988 until October 2002, about 2100 events were recorded by at least four of the national seismic network stations. These were relocated by means of an iterative procedure described in Capizzi et al. (2001).

The initial velocity model used for the iterative optimization process derives from a $3 \mathrm{D}$ model obtained by synthesizing the $2 \mathrm{D}$ interpretation along numerous WARR seismic profiles recorded in the Sicilian-Calabrian area beginning from 1968, and constraining the interpolation among the profiles by 3D Bouguer anomaly interpretation. Some high-density wide-angle seismic profiles acquired in the context of the Crop Mare II Project, an intensive programme of seismic active exploration (Caielli et al., 2003), and the relative gravimet- ric data, were used to model the $\mathrm{T} 1$ and $\mathrm{T} 2$ transects reported in fig. 1, which cross the Southern Tyrrhenian area (Chironi et al., 2000).

The iterative procedure adopted to locate the entire Tyrrhenian earthquake data set is based on the observed $P$-wave arrival times inversion by HYPO71PC and the subsequent correction of the velocity model aimed at reducing both the root-mean-square of time residuals and their correlation in the epicentral distance and hypocentral depth domains. To balance the known tendency of HYPO71PC to find solutions corresponding to relative minima of the misfit function, numerous locations were carried out with different criteria for each of the tested velocity models by changing the initial hypocentral parameters. Within the set of solutions obtained for each event, the one with the smallest RMS was selected. Before each inversion, the estimates of the mean station residuals and of the observed data weights were adjusted on the basis of the previous inversion results.

The relocation of the whole data set thus led to a mean-station residuals distribution which seems to appropriately represent the local velocity anomalies in the area, since it is significantly anti-correlated with the Bouguer anomaly distribution. Moreover, a reliable 1D velocity

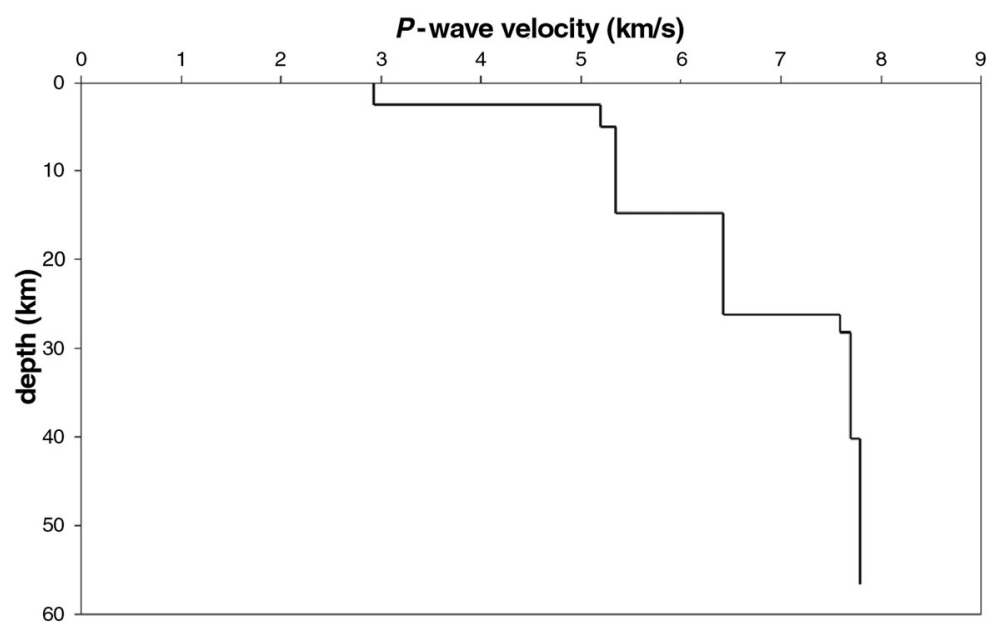

Fig. 9. 1D $P$-wave velocity model defined for the Southern Tyrrhenian Sea. 
model was defined for the Southern Tyrrhenian area. Such a model, shown in fig. 9, is in good agreement with the information provided by the integrated interpretation of refraction and wideangle reflection seismic profiles, and of the corresponding gravity profiles. It is characterized by a rather slow lower crust and by a crust-mantle transition zone between $\sim 26$ and $28 \mathrm{~km}$.

A first accuracy index of the hypocentral coordinate, velocity model and mean-station residual estimates is the mean RMS value, which proved to be equal to $\sim 0.14 \mathrm{~s}$, the same order of magnitude as the expected standard error in the first-arrival time readings under average $\mathrm{S} / \mathrm{N}$ conditions, and, therefore, not significantly reducible.

The distribution of the hypocenters reveals the presence of two main seismogenic zones (fig. 10a). In the first one, located in the eastern portion of the Southern Tyrrhenian Sea, about 480 events are concentrated around a NW dipping plane with a slope angle of $\sim 58^{\circ}$ down to depth of more than $400 \mathrm{~km}$. These events depict the tectonic lineaments related to the Ionian lithospheric slab diving beneath the Calabrian Arc (Guerra et al., 2003).

The seismicity of the second zone is contained within the Southern Tyrrhenian thinned
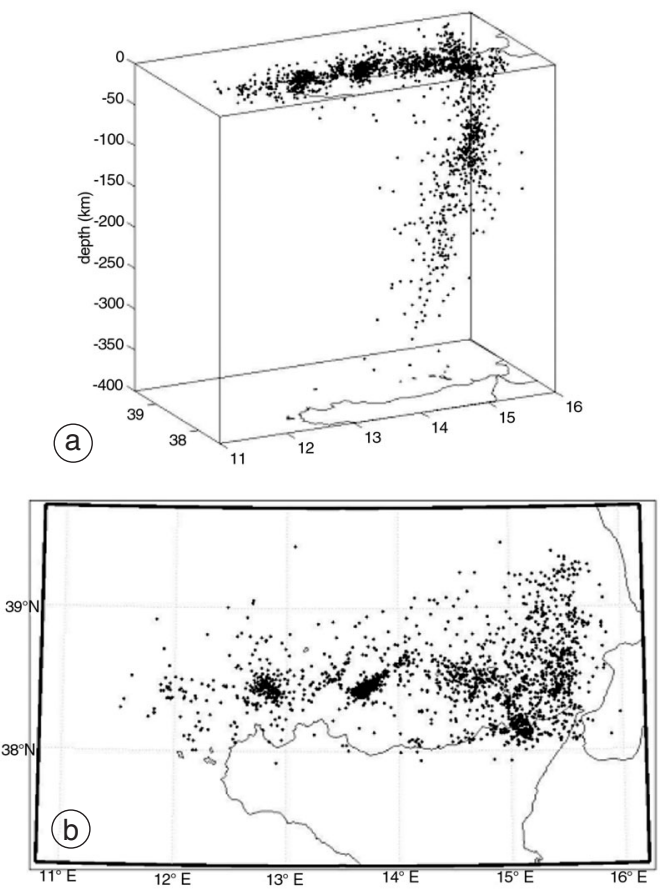

Fig. 10a,b. Distribution of hypocenters (a) and epicenters (b) of the 2100 earthquakes occurred in the Southern Tyrrhenian area between 1988 and October 15, 2002.

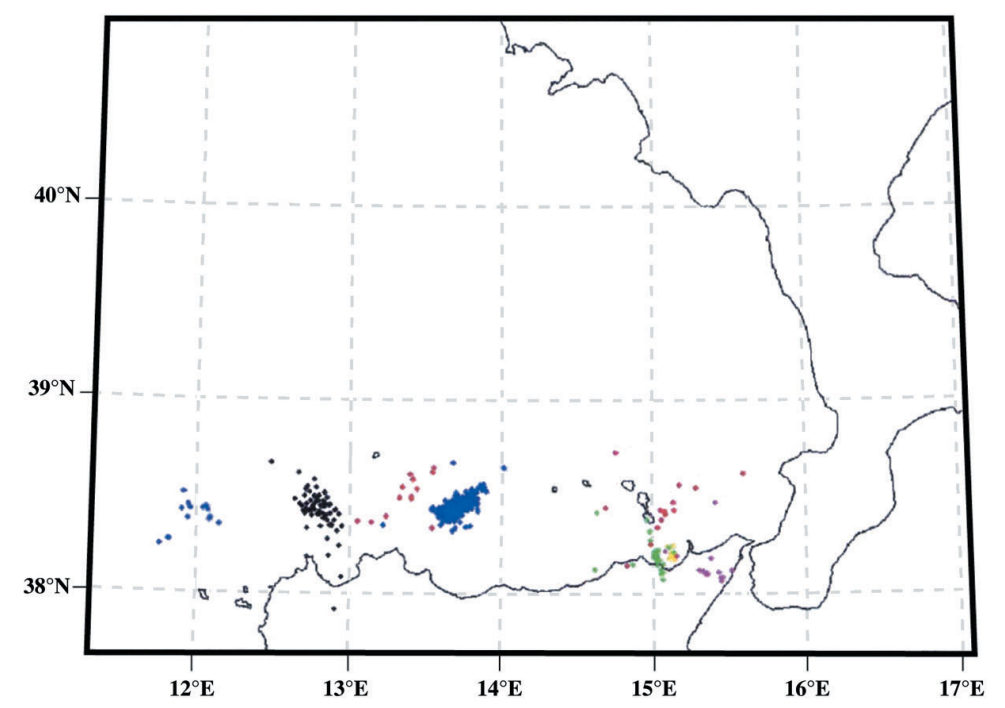

Fig. 11. Map of the clusters containing at least 10 events reconstructed for the Southern Tyrrhenian Sea. 
crust, and is well clustered around a sub-horizontal regression plane dipping westwards and northwards at an average depth of about $10 \mathrm{~km}$. Here, the independent events' epicentres are characterized by a smooth distribution which presents a higher density along an E-W band more or less connecting Ustica and Eolie and probably following the northern margin of the Sicilian-Maghrebian Chain (fig. 10b).

The elastic deformation energy release connected to highest-magnitude events in this area generally takes the form of aftershocks, whose hypocenters are included in volumes characterized by a high-fracture density connected to the principal tectonic faults. In order to analyze the spatial distribution and the geometric features of the main clusters of the more recent seismicity, a method of seismic sequences detection was implemented and applied to the entire set of earthquakes. This method is based on the assumption that two events are causally dependent and thus belong to the same cluster if they satisfy proximity conditions in space and time. In particular, a double proximity condition, $\Delta s<\delta_{s}$ and $\Delta t<\delta_{t}$, was defined in this analysis, with $\Delta s$ and $\Delta t$ being the space and time distances between a couple of hypocenters, and $\delta_{s}$ and $\delta_{t}$ being two threshold values. Therefore, a seismic sequence, which is a set of causally connected events, is such that each of its elements is characterized by a distance, both in space and in time, which is lower than the fixed thresholds $(35 \mathrm{~km}$ and 2 days in this application) from at least one other element of the cluster. Figure 11 maps the 8 aftershock sequences containing at least 10 events each. It can be observed that the distribution of clusters also has a prevalent concentration along the UsticaEolie band.

\section{The September 2002 seismic sequence}

The 2002 Palermo seismic sequence which occurred after the 6th September main shock, which had magnitude $M_{l}=5.6$, is located inside the hinge zone and is characterized by about 540 earthquakes recorded by the INGV national network between 6th September and 15th October, 2002.
The time distribution of the daily frequencies of these events (fig. 12) shows decreasing activity until 27th September, with a trend which can be described by Omori's power law. Several estimates of the power-law exponent, ranging around 0.7 , were obtained both by the least-squares and the maximum-likelihood method, both on the data set as a whole and on

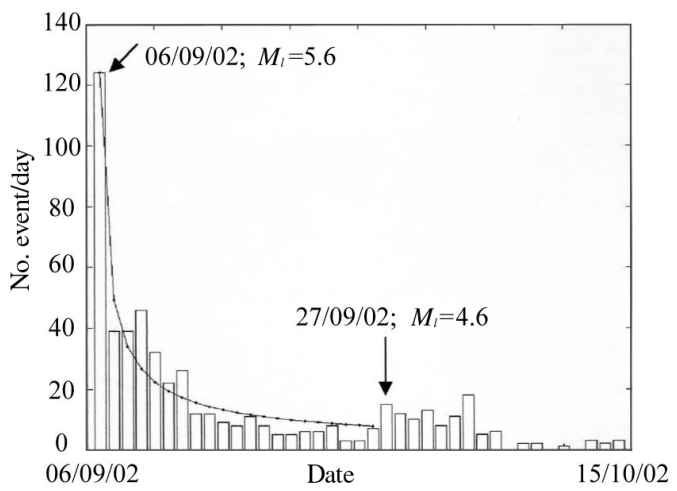

Fig. 12. Time distribution of the daily frequencies of the events recorded from 6th September to 15th October 2002 (bars) and the curve expressing the Omori's Law from 6th September to 27th September 2002 (solid line).

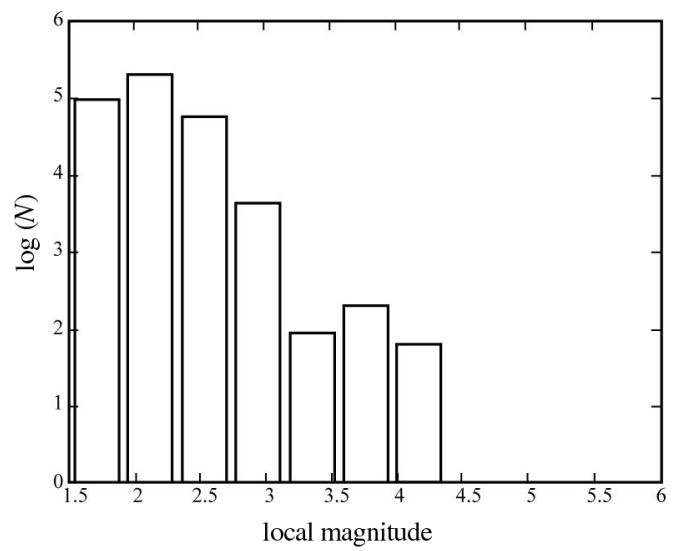

Fig. 13. Frequency-magnitude distribution of the events recorded from 6th September to 15th October 2002. 
truncated subsets. These estimates may be biased because of the incompleteness of the data set (fig. 13) for local magnitudes lower than $\sim 2$.

After 27th September, when the second highest-magnitude event occurred $\left(M_{l}=4.6\right)$, a new increase in seismic activity was observed, indicating an evolution of the phenomenon, characterized by multiple time clustering.

The $\sim 540$ events of the studied sequence were relocated using the same procedure adopted for the events of the whole Southern Tyrrhenian area. The double-couple focal mechanism and the moment tensor of the seven events having the largest magnitude among those recorded in this period were calculated (fig. 14 and table I). They indicate compressional mechanisms with a right strike-slip component (the average strike and dip values for one nodal plane are $\sim 244^{\circ}$ and $\sim 48^{\circ}$ respectively) for all the events except for the one which occurred on 28th September, for which a slight left strike-slip component was observed. The strike of one of the nodal planes is characterised by a small variance. The strike values are reported in table I together with those of the dip and local magnitude.

The relocation was carried out keeping the velocity model unchanged with respect to the 1D velocity model defined for the Southern Tyrrhenian area. Instead, new mean values of the station residuals were estimated, since the amplitude of the azimuth and epicentral distance ranges for each station relative to the rays traveling from the cluster are sensibly narrower than those relative to the whole Tyrrhenian data set. The mean RMS value for the relocated hypocenters is $\sim 0.08 \mathrm{~s}$.

After relocation, the events of the 2002 seismic sequence are distributed within a seismogenic volume which seems to be included in a

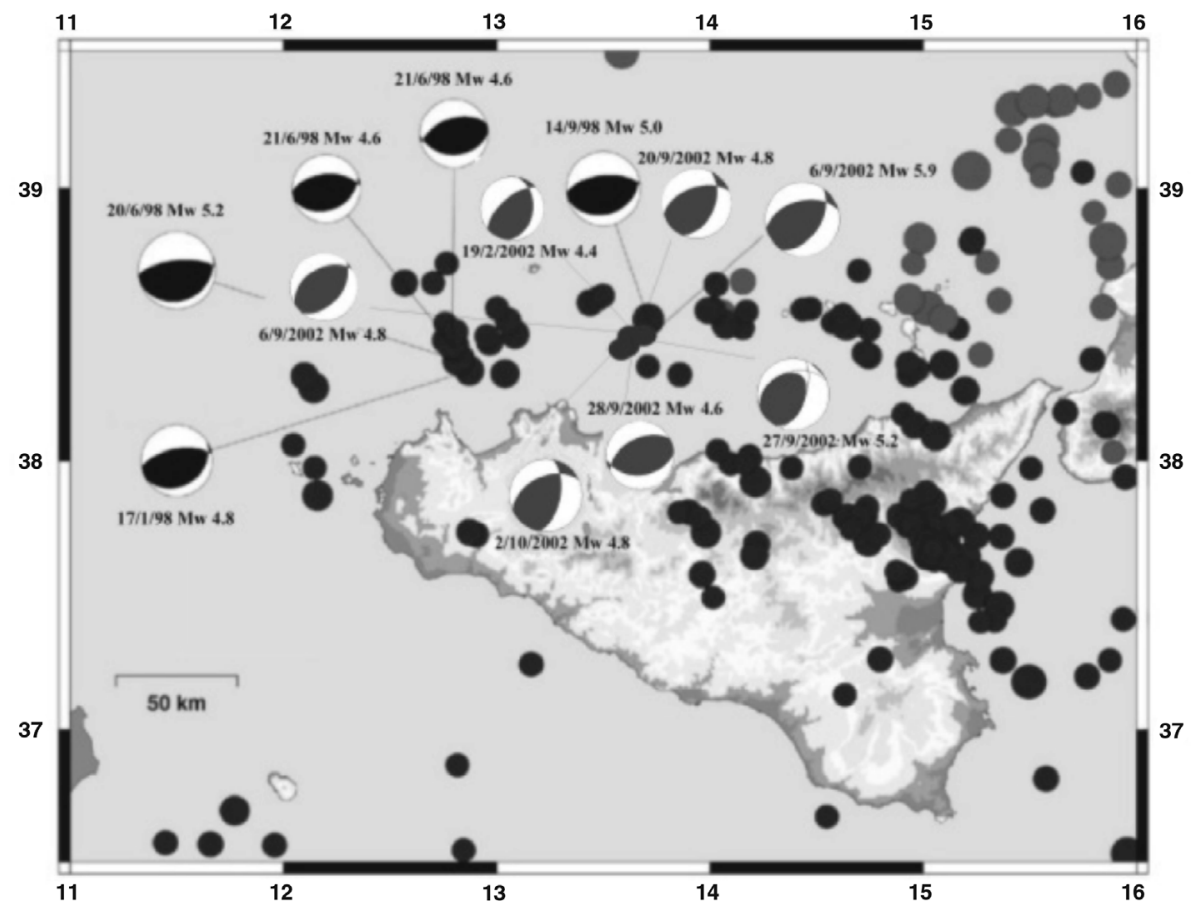

Fig. 14. Focal mechanisms of recent earthquakes in the Southern Tyrrhenian Sea-Sicily belt; the seven largest earthquakes of the seismic sequence started on 6th September 2002 are also shown (modified from INGV). 
Table I. Nodal planes of the focal mechanisms calculated for the 7 main events of the 2002 Southern Tyrrhenian Sea seismic sequence. The average strike and dip values for these planes are, respectively, $\sim 244^{\circ}$ and $\sim 48^{\circ}$.

\begin{tabular}{cccc}
\hline \hline Date & $M_{l}$ & Strike & Dip \\
\hline $06 / 09 / 2002-01.21$ & 5.6 & 255 & 49 \\
$06 / 09 / 2002-01.45$ & 4.3 & 240 & 44 \\
$10 / 09 / 2002-02.32$ & 4.0 & 229 & 34 \\
$20 / 09 / 2002-23.06$ & 4.2 & 250 & 47 \\
$27 / 09 / 2002-06.10$ & 4.6 & 248 & 38 \\
$28 / 09 / 2002-02.46$ & 4.1 & 242 & 42 \\
$02 / 10 / 2002-22.57$ & 4.3 & 245 & 47 \\
\hline
\end{tabular}

parallelepiped whose height is about $26 \mathrm{~km}$, one of whose horizontal sides is about $35 \mathrm{~km}$ whilst the other is about $15 \mathrm{~km}$. In particular, the distribution of the hypocenters appears to be clustered around a plane with strike $234^{\circ}$ and dip $83^{\circ}$, having a root-mean-square distance from it equal to $\sim 2 \mathrm{~km}$ (fig. 15 ).

\subsection{Hypocentre assessment}

Considering that the arrival times used in the location procedure had not yet been merged with the numerous observations from the mobile seismic network deployed during the months of September and October 2002 and from the 5 stations of the new Belice local array (Western Sicily) of the INGV, it seemed wise to perform a number of tests in order to evaluate the reliability of the hypocentral distribution obtained. These consisted in analyzing the random errors on the hypocenter positions connected with the arrival-time reading uncertainties and with the dependency of the solution on the a priori assumed locations, as well as in finding out whether the hypocenter distribution could be affected by systematic errors connected with the inappropriate recording layout.

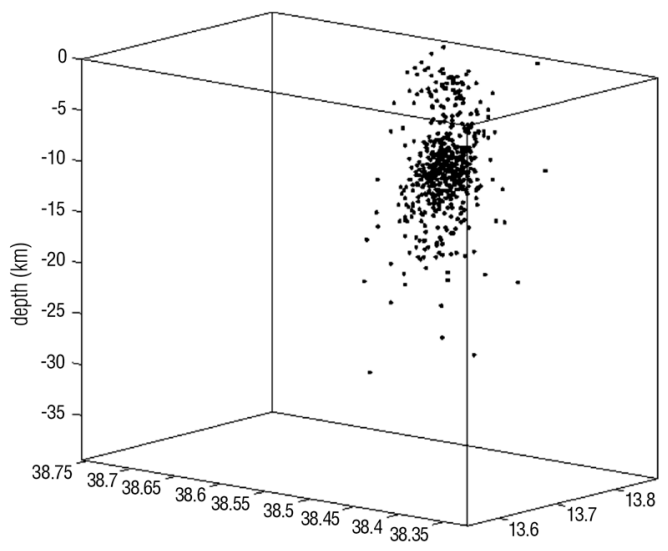

Fig. 15. Relocated hypocenters distribution of the $\sim 540$ earthquakes recorded from 6th September to 15th October 2002.

In order to evaluate the maximum volume of the cluster of hypocenters, accounting for possible location errors related to uncertainty in the arrival times, a test based on the Montecarlo technique was performed. It consisted in the relocation of the 54000 events obtained by randomly perturbing 100 times each of their observations. The normal distribution standard deviation of the time perturbations was set to $0.1 \mathrm{~s}$, because the mean RMS of the cluster location had been found to be equal to $0.08 \mathrm{~s}$. The distribution of the 54000 hypocenters (fig. 16) indicates that volume, shape and extension were left unchanged by the perturbation and only a few events were located with considerable uncertainty.

A further test was carried out with the purpose of evaluating the location errors connected with the hypocenter starting positions. It consisted of various perturbations of the events' initial hypocenter parameters, moving them away from the cluster in random directions up to distances of $40 \mathrm{~km}$. It was observed that a large portion of the seismic events was always relocated within the boundary of the cluster described above, whilst in some inversions $\sim 60$ of the events recorded by only 4 or 5 stations were located in a new small cluster with an RMS value close to the absolute minimum (fig. 17). The center of this cluster is about $60 \mathrm{~km}$ west of the 
center of the main one, near the area where the 1998 seismic sequence occurred. The result of this test indicates that since the constraints for the inversion of some events are poor and the algorithm in different iterations stops in one of the two relative minima positions, both the clusters should be considered acceptable until the events are relocated using the complete data set.

In order to evaluate any possible systematic errors introduced in the estimates because of the

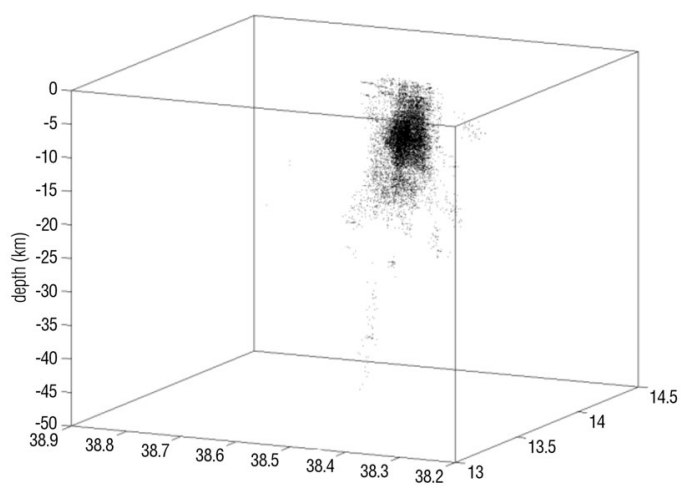

Fig. 16. Hypocenters distribution of the 54000 earthquakes relocated in the Montecarlo test.

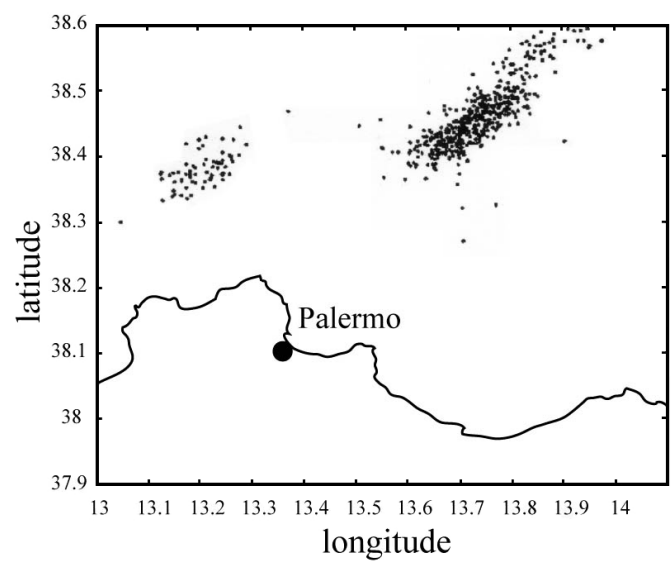

Fig. 17. Epicenters distribution of the 540 earthquakes relocated for evaluating the location errors connected with the hypocenter starting positions. inappropriate arrangement of the seismic network with respect to the seismic events, two different tests were performed. In the first, the 6th September main shock was relocated 540 times using its observed times relatively to the different arrays that had recorded the aftershocks. The test results indicate a tendency of the inversion to shift the less constrained event epicenters towards NW, with a maximum displacement of about $17 \mathrm{~km}$. As a consequence, such an error cannot be the source of the evident NE-SW strike of the sequence-event distribution, and the latter can therefore be considered a reliable geometric feature of the cluster. Nevertheless, it is possible to hypothesize a slight erroneous widening of the cluster about its mean plane.

In order to obtain more accurate information about systematic location errors connected with the geometry and number of stations of the seismic array, a further test was performed on a set of 50 synthetic hypocenters randomly generated around the 6th September main shock. The synthetic events were distributed over an area about $30 \mathrm{~km}$ by $30 \mathrm{~km}$ wide and in a depth range from 0 to $45 \mathrm{~km}$. The travel times between each of the hypocenters and part of the stations of the national seismic network were perturbed 60 times. The tests were conducted considering the travel times relative to the following four configurations of the seismic network: 1) the 32 stations which recorded the 6th September main shock; 2) the 17 stations located south of the main shock; 3) the 15 stations located north of the main shock; and 4) the 4 stations located south of the main shock which recorded the largest portion of the events localized with only four arrival times. With the purpose of minimizing the random component of the hypocenter displacement vectors, the inversion of these sets of data was carried out using the true initial hypocentral parameters and velocity model.

For each of the 50 hypocenters the mean displacements $\left\langle\boldsymbol{v}_{i}\right\rangle$ of the 60 were calculated. To evaluate whether a systematic component of such vectors existed, both the mean $\langle\boldsymbol{v}\rangle$ of the 50 vectors $\left\langle\boldsymbol{v}_{i}\right\rangle$ and a parameter $s$ were calculated, the latter indicating whether the mean can be considered a significant estimate of the systematic errors. The parameter $s$ is defined as the ratio between the standard deviations of the vec- 
tors $\left\langle\boldsymbol{v}_{i}\right\rangle$ and of the 3000 displacement vectors. Values of $s$ close to 0 indicate the probable existence of systematic location errors, whilst values close to 1 indicate that no systematic component can be detected in the estimates variability.

Table II. Results of the tests conducted considering the travel times relative to four configurations of the seismic network (see text for explanations).

\begin{tabular}{cccc}
\hline \hline Configuration & $\begin{array}{c}(v) \\
(\mathrm{km})\end{array}$ & $\begin{array}{c}\text { Azimuth of }(v) \\
(\text { degrees })\end{array}$ & $s$ \\
\hline 32 stations & 0.17 & 3.1 & 1.81 \\
17 stations & 0.25 & 162.76 & 1.06 \\
15 stations & 0.56 & 101.12 & 0.83 \\
4 stations & 0.81 & 59.92 & 0.54 \\
\hline
\end{tabular}

The results obtained, reported in table II, show that only for the events recorded by the four very decentralized stations is a systematic location error probably observable.

In conclusion, the results of the tests carried out to verify the reliability of the parameters relative to the hypocenter distribution shape and position evince a high stability of the solutions, and show that no appreciable deformation and mislocation effects on the seismogenetic volume of the cluster are observable.

\section{Conclusions}

The hypocentral distribution of the about 2100 events recorded from 1988 to October 2002 emphasizes the presence in the Southern

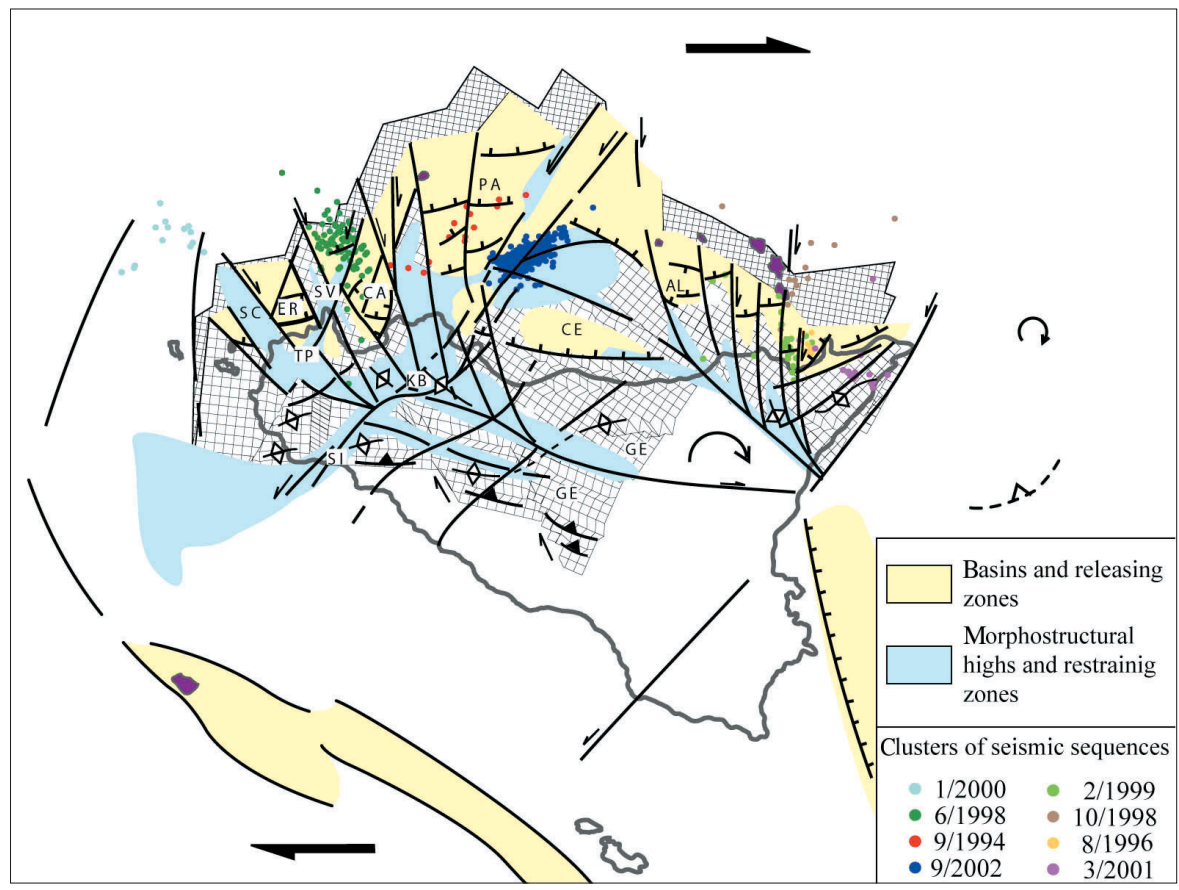

Fig. 18. Localization of the seismic clusters of fig. 11 on the kinematic deformational model of fig. 5, showing the compatibility of seismicity with the main structural lineaments (modified from Giunta et al., 2002a): $\mathrm{AL}=$ Alicudi Basin; $\mathrm{CA}=$ Castellammare Basin; $\mathrm{CE}=$ Cefalù Basin; $\mathrm{ER}=$ Erice Basin; $\mathrm{GE}=$ Gela nappe; $\mathrm{KB}=$ Kumeta-Busambra high; $\mathrm{PA}=$ Palermo Basin; $\mathrm{SC}=$ Scuso bank; $\mathrm{SI}=$ Sicani Mts.; SV=San Vito high; $\mathrm{TP}=$ Trapani Mts. 
Tyrrhenian Sea of two seismogenetic provinces. In the western one a seismogenetic layer, dipping slightly towards north and west, is localized at an average depth of about $10 \mathrm{~km}$ within the thinned-Tyrrhenian crust made by the Maghrebian units.

The crustal seismicity of this sector of the Southern Tyrrhenian Sea is mostly located in the hinge zone between the portion of the basin characterized by the strongest crustal thinning, and the sector of the Sicily belt which had already emerged. This hinge zone is the prevailing feature of the E-W trending-dextral shear zone affecting the wide area extending from the southernmost ending of the Tyrrhenian abyssal plain towards the Sicilian Channel.

The recent deformation pattern, observed on land and extrapolated to the offshore area, is characterized by a grid of high-angle faults represented mainly by synthetic right-lateral and antithetic left-lateral fault systems, characterized by the occurrence of both restraining/uplifting and releasing/subsiding zones. This fault grid accommodates the brittle strain developing in response to the current stress field acting in the area, which is characterized by a maximum principal axis trending NW-SE, as emerges from both structural and seismological data.

In order to better constrain a seismotectonic model using the seismological data of the Southern Tyrrhenian, the hypocenters of about 2100 earthquakes which occurred from 1988 to 2002, comprising the main shock and about 540 aftershocks of the Southern Tyrrhenian seismic sequence which started on 6th September 2002, were relocated and analyzed in detail. In order to look for possible correlations between seismicity and seismogenetic faults, the heterogeneity of the data set was also taken into account, since there are more seismological data for the offshore sector than the onshore one, where structural data are more abundant.

Moreover, the seismicity was observed to be coherent with the kinematic model, indicating the main active seimogenetic structural alignments in Northern Sicily and the Southern Tyrrhenian region. The reconstructed clusters of events significantly correlate with the main tectonic lineaments (fig. 18) of the Southern Tyrrhenian-Sicily system.
In particular, the recent seismic activity is mainly concentrated along structures with inverse and/or transcurrent kinematics. The focal mechanisms relative to the main events, available for the western sector of the Southern Tyrrhenian, indicate an inverse kinematics on the NE-SW trending medium-high-angle nodal planes.

The cluster of the Palermo seismic sequence seems to fit well the seaward prolongation of the NE-SW trending left-lateral transpressive structure which borders eastwards the Palermo mountains. This structural lineament (Giunta et al., 2000b, 2002a,b) may perhaps be connected with the so-called Belice seismogenetic zone.

\section{Acknowledgements}

The authors thank I. Guerra for his critical reviews of the manuscript; they also thank the Department of Hydraulic Engineering and Environmental Application of Palermo University for kindly providing the LANDSAT images of Northern Sicily, and Drs. S. Carnemolla and A. Priolo (CTM/Telespazio) for their processing.

This research was supported by funds granted to G. Giunta, D. Luzio, P. Renda and G. Cello by the Ministry of University and Research and by Palermo University funds.

\section{REFERENCES}

Boccaletti, M., C. Conedera, P. Dainelli and P. Gocev (1982): The recent (Miocene-Quaternary) rhegmatic system of Western Mediterranean region. A new model of ensialic geodynamic evolution in a context of plastic/rigid deformation, J. Pet. Geol., 5 (1), 31-49.

Caielli, G., P. Capizzi, A. Corsi, R. De Franco, D. Luzio, L. De LuCA and M. Vitale (2003): Wide-angle sealand connections as an integration of the Crop Mare II Project, in Crop Atlas: Deep Seismic Reflection Profiles of the Italian Crust, edited by D. ScroccA, C. Doglioni, F. Innocenti, F. Manetti, A. Mazzotti, L. Bertelli, L. Burbi and S. D'OfFizi, Memorie Descrittive della Carta Geologica d'Italia (Servizio Geologico Nazionale, Roma), 62, 55-74.

Capizzi, P., L. De LucA, D. LuZio and M. Vitale (2001): Procedura di ottimizzazione di un modello di velocità 1d applicata ai terremoti locali dell'area tirrenica, in Atti $20^{\circ}$ Conv. Ann. Gr. Naz. Geofisica Terra Solida, CNR, Roma (CD-ROM).

Cello, G. (1997): Fractal analysis of a Quaternary fault ar- 
ray in the Central Apennines, Italy, J. Struct. Geol., 19, 945-953.

Chironi, C., L. De Luca, I. Guerra, D. Luzio, A. MoretTI, M. Vitale and Sea Land Group (2000): Crustal structures of the Southern Tyrrhenian Sea and the Sicily Channel on the basis of the M25, M26, M28, M39 WARR profiles, Boll. Soc. Geol. It., 119, 189-203.

Cowie, P.A., C. VAnNeste and D. SornetTe (1993): Statistical physics model for the spatio-temporal evolution of faults. J. Geophys. Res., 98, 21809-21821.

FinetTi, I. and A. Del Ben (1986): Geophysical study of the Tyrrhenian opening, Boll. Geofis. Teor. Appl., 28, 75-155.

FinetTi, I, F. Lentini, S. Carbone, S. Catalano and A. DEL BEN (1996): Il sistema Appennino MeridionaleArco Calabro-Sicilia nel Mediterraneo Centrale: studio geologico-geofisico, Boll. Soc. Geol. It., 115, 529-559.

GHISETTI, F. and L. VezZANi (1984): Thin-skinned deformation in Western Sicily, Boll. Soc. Geol. It., 103, 129-157.

GiunTA, G. (1985): Problematiche ed ipotesi sul bacino numidico nelle Maghrebidi Siciliane, Boll. Soc. Geol. It., 104, 239-256

Giunta, G., F. Nigro and P. REndA (2000a): Extensional tectonics during Maghrebides chain building since Late Miocene: examples from Northern Sicily, Ann. Soc. Geol. Pol., 70, 81-98.

Giunta, G., F. Nigro, P. Renda and A. Giorgianni (2000b): The Sicilian-Maghrebides Tyrrhenian Margin: a neotectonic evolutionary model, Boll. Soc. Geol. It., 119, 553-565.

Giunta, G., F. Nigro, P. Renda, F. Andaloro, A. GiorGIANNI and V. SPARACINO (2002a): The structural and morphotectonic framework of the NW Sicilian Maghrebides, in a seismotectonic perspective, Studi
Geologici Camerti, no. spec., 103-117.

Giunta, G., F. Nigro, D. LuZio, G. D'anna, E. Tondi, P Renda, G. Cello, A. Giorgianni, L. De Luca and M. VITALE (2002b): Sismicità e tettonica recente in Sicilia nord-occidentale e nel Tirreno meridionale per un modello sismotettonico preliminare, in Atti $21^{\circ}$ Conv. Ann. Gr. Naz. Geofisica Terra Solida, CNR, Roma (CD-ROM).

Guerra., I., A. Gervasi, P. Harabaglia, G. Neri and B. ORECCHIO (2003): Recent instrumental seismicity in the Calabrian Arc region and its relationship to tectonic lineaments, in Workshop on «Seismogenic faulting and seismic activity in the Calabrian Arc region», Taormina, 44-45.

Mandelbrot, B.B. (1982): The Fractal Geometry of Nature (Freeman Press, San Francisco, CA), pp. 121.

Nigro, F., P. RENDA and G. ARISCO (2000): Tettonica recente nella Sicilia nord occidentale e nelle Isole Egadi, Boll. Soc. Geol. It., 119, 307-319.

Pepe, F., G. Bertotti, F. Cella and E. Marsella (2000): Rifted margin formation in the south Tyrrhenian Sea: a high-resolution seismic profile across the north Sicily passive continental margin, Tectonics, 19 (2), 241-257.

Sornette, A., P. Davy and D. SornetTe (1990): Growth of fractal fault patterns, Phys. Rev. Lett., 65, 2266-2269.

WALSH, J.J. and J. WATTERSON (1992): Populations of faults and fault displacements and their effects on estimates of fault-related regional extension, J. Struct. Geol., 14, 701-712.

(received January 8, 2004 accepted May 19, 2004) 